\title{
The Frame Structure Design of three Lifting Point Dummy ROV
}

\author{
Xingwei Guo ${ }^{1, a}$, Jie Song ${ }^{1, b}$ and Zhenzhong Liu $^{2, c}$ \\ ${ }^{1}$ Offshore Oil Engineering Co., Ltd. Tianjin, China; \\ ${ }^{2}$ Tianjin Key Laboratory of the Design and Intelligent Control of the Advanced Mechatronical System, \\ Tianjin University of Technology, Tianjin, China. \\ aguoxw@mail.cooec.com.cn, bsongjie@mail.cooec.com.cn, ${ }^{\mathrm{C} l i u s d c n @ g m a i l . c o m}$
}

Keywords: Lifting point, dummy ROV, frame structure.

\begin{abstract}
Research the depth of 3000m Work-Class ROV as mock object and develop a ROV for land test. This device is set three lifting point in the top. The rope connecting the front two lifting point is fixed, the rope connecting the rear lifting point change the length by motor. All of those lifting point are in order to achieve the function of forerake and hypsokinesis. The Dummy ROV can displace the real ROV to simulate the land construction, improve the efficiency of ocean construction and reduce the cost of experiment.
\end{abstract}

\section{Introduction}

With the lots of applications of the ROV technology in the civil and military, scientists do a lot of research on related technologies and develop the ROV with the functions of observe, survey and operation. But with the deepening of the ocean development, pure observation and measurement can't meet people's needs. There is an increasing demand for ROV operation ability. But the current underwater operation system is more complex and relatively large volume. Construct at the bottom of the sea often need the help from the ROV. In order to verify the construction plan, ensure the construction efficiency, workers will use the ROV or Dummy ROV on land to simulation construction. Using the real ROV cost lot, and the current Dummy ROV do not have the function of forerake and hypsokinesis.

So, in this paper, we research the depth of $3000 \mathrm{~m}$ Work-Class ROV as mock object; develop a ROV for land test. This Dummy ROV is set three suspending point in the top. And the rope which connected the rear lifting point changed the length by motor. And this can come true the function of pitching and tilting. Dummy ROV can be used for the simulation of construction land, in order to achieve the purpose of improve ocean construction efficiency, reduce cost.

\section{Steel frame design requirements}

The steel frame is applied subsea production system integration test simulator dedicated channel check, its function is to complete various postures and functional test by simulating underwater ROV for hollow structure, so the structural design's limits is to meet the normal operation of the equipment.

The equipment is the subsea production system integration testing simulator dedicated channel check, it will be suspended in the air in the course and simulate underwater ROV's various working posture, the steel structure demand independently completed before and after pitching pose adjustment and positioning.

\section{The main content should be considered in the design}

\subsection{The effect of temperature}

Steel is a kind of thermal expansion coefficient is larger materials and Steel Structure components buckling failure is often the first on the strength of the material damage to occur. Based on steel components in axial compression prone to buckling and the internal forces caused by the change of 
temperature and deformation has a great impact on structural safety, meanwhile, this equipment is used for offshore environment with large temperature difference between day and night, so we should fully consider the loads produced by steel components when the temperature changes in the design.

\subsection{Corrosive effect}

In the coastal ocean climate conditions, Corrosion of steel structure is particularly serious. Therefore, in order to ensure the normal operation of equipment and security conditions, the frame body structure and its affiliated members all select SS304 stainless steel.

\subsection{The control of before and after pitching pose}

In order to make steel structure independently completed before and after pitching pose adjustment and positioning, we should set up three hanging points on the top of the steel structure and place aft winch and the winch rope's guide wheels. In the normal transport and lifting process, you can use three fixed lifting points.

In the working process, the first two lifting point and the tail rope winch control the length of the wire rope winch receive to realize the control of the equipment before and after the pitch angle.

\subsection{Equipment used in the process of collision protection}

In actual working process of the simulator, it is inevitable that collision with the obstacles. We should set the anti-collision device in the front frame of the steel structure and bottom respectively for the effective protection and the safety of the equipment, and equipped with protection rubber gasket around the equipment.

\section{The specific design of steel structure frame}

\subsection{The design of steel structure main body frame}

In the design process of simulator steel frame, the main body size referenced the size of the foreign same type underwater ROV and considered the actual working condition of the simulator and the job requirement at the same time, we ultimately determine its periphery size is: (length) $\mathrm{L}=3200$, (wide) $\mathrm{D}=1700$, (high) $\mathrm{H}=1800$, and set up four foot of $\mathrm{H}=100$ at the bottom of the frame for convenient transportation of the equipment.

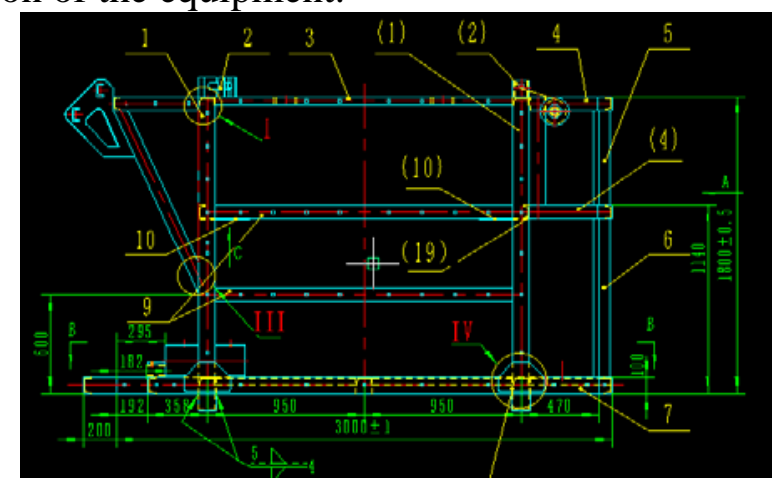

Fig. 1 Steel structure frame diagram

\subsection{The design of steel structure frame longitudinal beam}

In actual working process of the simulator, the frame longitudinal beam is one of the main stressed components, mainly bear axial pulled at the ends of the lift and considering the actual working environment at the same time, the preliminary selection of channel steel material is SS304. We know the axial deformation of suspension under normal working condition of the frame is complied with relevant requirements by applying stress analysis software. 


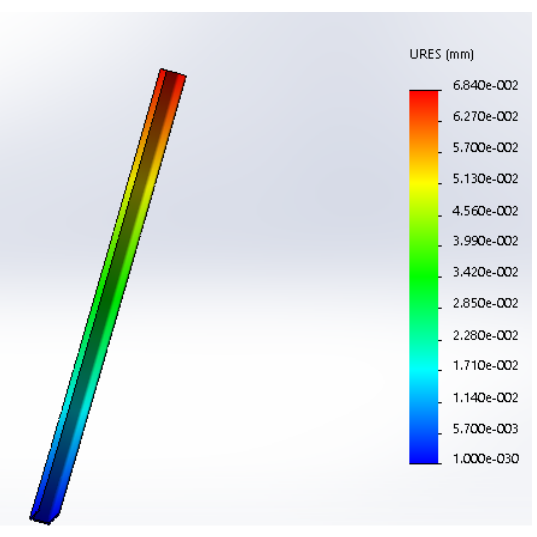

Fig. 2 Steel structure frame girder stress diagram

\subsection{The design of steel structure before collision avoidance}

Through the simulator of the actual working process of the analysis, we design the following institutions as a front fender of the equipment: (As shown in the figure below 25)

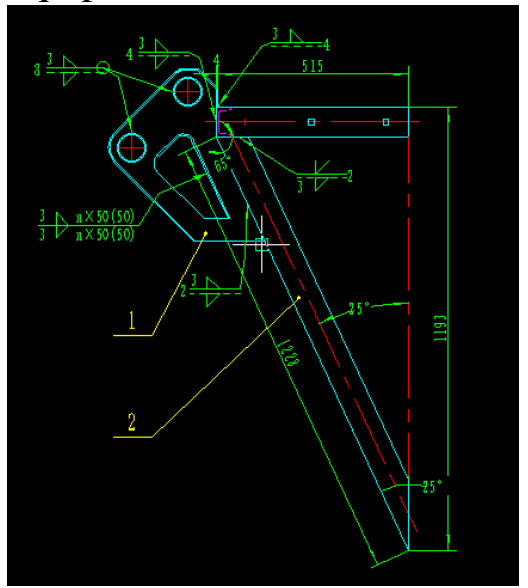

Fig. 3 The steel structure before the collision

For better absorption of accidental collision energy and protect the equipment, the main body of collision avoidance (number 1) using $4 \mathrm{t}=4$ piece of anti-collision support plate and the $80 \times 3 \Phi$ stainless steel pipe welding structure.

\subsection{The framework design of lifting point}

In order to optimize the force of lifting hook in the normal transport, process of lifting and work, especially the first two hooks, setting the lifting point on the top of steel structure, make the first two lifting point around the rotated 45 degrees. Hang locks are not limited to the direction of the ear plate and don't stress bending and deformation when hoisting. Thus avoid the excessive bending stress concentration and the locks premature damage. (The stress analysis diagram-picture 26, the exact location of the lifting point-picture 27)

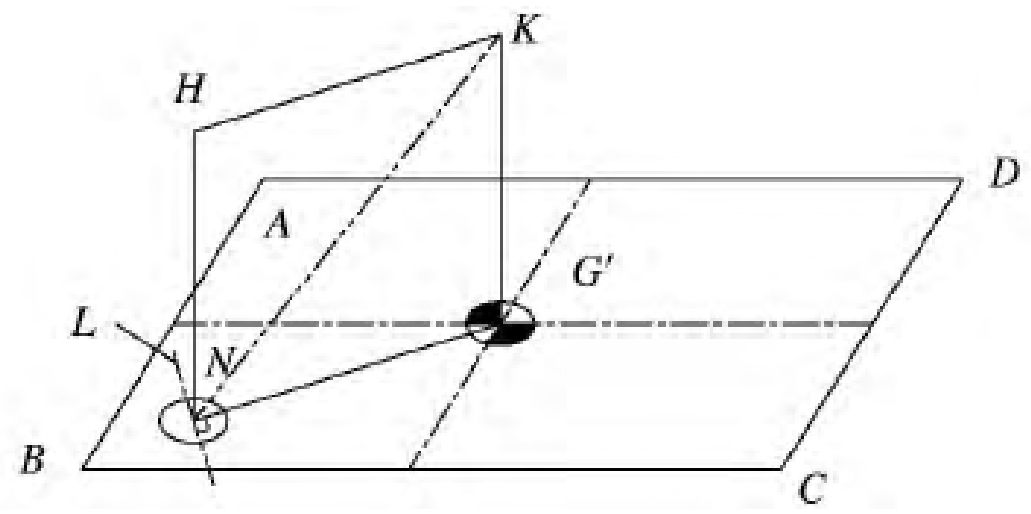

Fig. 4 Sketch map of Lifting point force diagram 


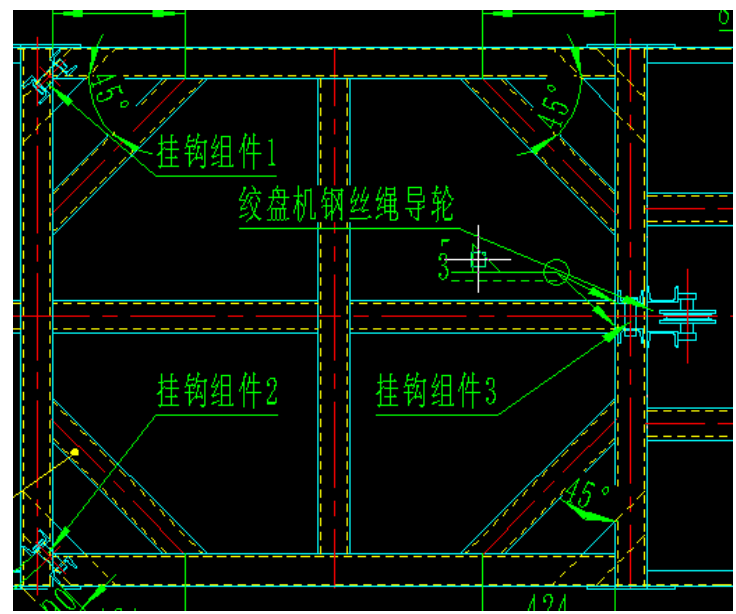

Fig. 5 Sketch map of Lifting point and guide wheel position
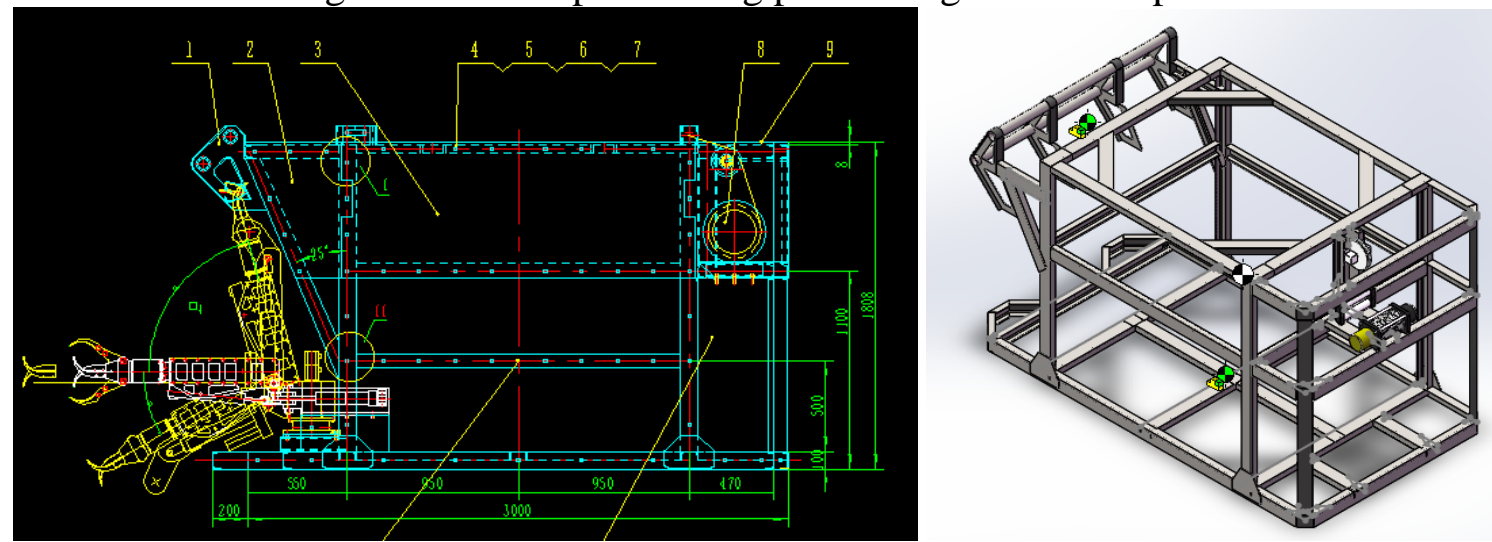

Fig. 6 General drawing of steel structure framework

This part introduces the ROV simulator, steel structure design, including the design of the steel structure and to meet the various requirements and constraints, equipment in the course of suspension design of hoisting position. According to the actual working condition, conform the frame in design centre sill component selection SS304 stainless steel channel and anti-collision component design. Physical objects as shown.

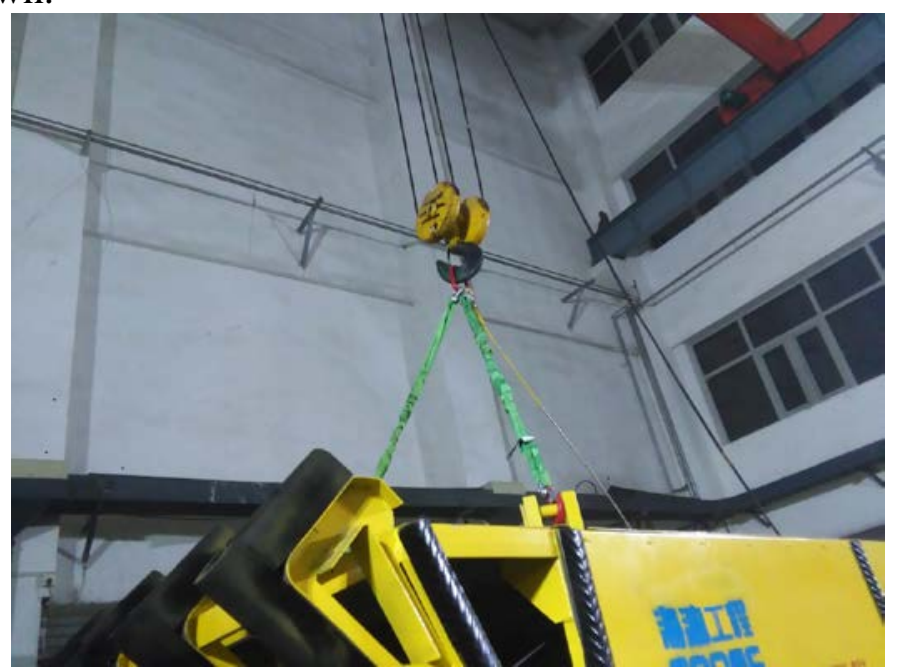

Fig. 7 Dummy ROV real figure

\section{Summary}

Experiments show that the Dummy ROV can realize the function of forerake and hypsokinesis. By installed the multifunctional manipulator in the front can replace real the ROV. On land validation underwater construction schemes, in order to achieve the goal of land simulation. 


\section{References}

[1]. Hosseini M, Seyedtabaii S. Robust ROV path following considering disturbance and measurement error using data fusion. Applied Ocean Research. Vol. 54 (2016), p. 67-72.

[2]. Soylu Serdar, Proctor Alison A, Podhorodeski Ronp, et al. Precise trajectory control for an inspection class ROV. Ocean Engineering. Vol. 111(2016), p. 231-236.

[3]. Le Khoa Duy, Nguyen Hung Duc, Ranmuthugala Dev, et al. A heading observer for ROVs under roll and pitch oscillations and acceleration disturbances using low-cost sensors. Ocean Engineering. Vol. 110(2015), p. 152-162.

[4]. Chowdhury T, Sathianarayanan D, Dharani G, et al. Failure Analysis of Fasteners in a Remotely Operated Vehicle (ROV) System. Journal of Failure Analysis and Prevention. Vol. 15(2015), No. 6, p.915-923. 